\title{
Efeito do Período de Exposição a Concentrações de Diquat no Controle de Plantas De Egeria densa, Egeria najas E Ceratophyllum demersum ${ }^{1}$
}

\author{
Effect of the Period of Exposure to Diquat Concentrations on the Control of Egeria densa, \\ Egeria najas and Ceratophyllum demersum
}

MARTINS, D. ${ }^{2}$, COSTA, N.V. ${ }^{3}$, DOMINGOS, V.D. ${ }^{3}$, RODRIGUES, A.C.P. ${ }^{4}$ e CARVALHO, F.T. ${ }^{5}$

\begin{abstract}
RESUMO - O período de permanência do herbicida na água pode ser influenciado pelo fluxo da água nos reservatórios e pela adsorção a partículas de argilas em suspensão, bem como pela degradação luminosa e por microrganismos. Objetivou-se com este trabalho avaliar diferentes periodos de exposição a concentrações do herbicida diquat no controle de Egeria densa, Egeria najas e Ceratophyllum demersum. O delineamento experimental utilizado foi o inteiramente casualizado, com quatro repetições, em esquema fatorial 6 x 5, mais uma testemunha. Foram testados seis periodos de exposição das plantas $(30,60,120,240$, 480 e 960 minutos) a cinco concentrações do herbicida diquat $(0,075 ; 0,15 ; 0,3 ; 0,6 ;$ e 1,2 ppm - produto comercial Reward $240 \mathrm{~g} \mathrm{~L}^{1}$ ). As avaliações de controle das plantas daninhas imersas foram visuais e, no final do experimento, foi avaliada a massa seca das plantas, para determinar a porcentagem de redução da biomassa. Observou-se que apenas 30 minutos de exposição das espécies imersas $E$. densa e $C$. demersum à concentração de 0,075 ppm foi suficiente para proporcionar redução da massa seca em ambas as espécies. Para controle de E. najas aos 7 DAA houve necessidade de um período maior que 120 minutos de exposição, considerando a mesma concentração do herbicida. Esses resultados evidenciam o potencial de uso do diquat no controle de plantas daninhas aquáticas imersas em locais que apresentam rápida renovação de água.
\end{abstract}

Palavras-chave: planta daninha aquática, plantas imersas, herbicida.

\begin{abstract}
The period of herbicide permanence in water can be influenced by the water flow in the reservoirs and the adsorption of clay particles in suspension, as well as by luminous degradation and microorganisms. Thus, the objective of this work was to evaluate the effect of different exposure periods to diquat concentrations on the control of Egeria densa, Egeria najas and Ceratophyllum demersum. The experimental design used was completely randomized, with four replicates, in a factorial scheme $6 \times 5$, plus a control. Six periods of plant exposure were tested (30, 60, 120, 240, 480 and 960 minutes) in relation to five diquat concentrations (0.075; 0.15 ; 0.3; 0.6 and $1.2 \mathrm{ppm}$ - commercial product Reward $240 \mathrm{~g} \mathrm{~L}^{-1}$ ). Visual evaluations of the immersed weeds were carried out and at the end of the experiment, shoot dry matter was evaluated to determine biomass percentage reduction. Based on the results obtained, it was concluded that exposure of only 30 minutes of the immersed species $\boldsymbol{E}$. densa and $\boldsymbol{C}$. demersum to 0.075 ppm concentration was sufficient to reduce shoot dry matter in both species. For $\boldsymbol{E}$. najas control after 7 DAA, an exposure period longer than 120 minutes was necessary, considering the same herbicide concentration. These results indicate the potential use of diquat to control immersed aquatic weeds in places presenting fast water renewal.
\end{abstract}

Keywords: aquatic weeds, immersed plants, herbicide.

1 Recebido para publicação em 13.6.2007 e na forma revisada em 12.2.2008.

2 Prof., Adjunto do Dep. de Produção Vegetal da FCA-UNESP, Fazenda Lageado, Caixa Postal 237, 18603-970, Botucatu-SP, $<$ dmartins@fca.unesp.br>; ${ }^{3}$ Doutor em Agronomia do Dep. de Produção Vegetal da FCA-UNESP, Botucatu/SP; ${ }^{4}$ Doutoranda em Agronomia do Dep. de Produção Vegetal da FCA-UNESP, Botucatu-SP, ${ }^{5}$ Prof., Adjunto do Dep. de Biologia e Zootecnia da FEISUNESP, Caixa Postal 31, 15385-000, Ilha Solteira-SP. 


\section{INTRODUÇÃO}

O equilíbrio dos ecossistemas aquáticos tem sido afetado pelas intervenções antrópicas, como a contaminação dos corpos hídricos pelo despejo dos dejetos urbano e industrial, além da construção de barragens, que transformam rios em grandes reservatórios de água; durante a sua formação pode ocorrer a eutrofização do ambiente, acarretando aumento expressivo da vegetação aquática no decorrer dos anos.

O crescimento excessivo de espécies aquáticas pode causar problemas para utilização dos reservatórios, como aumento da taxa de evaporação, diminuição da qualidade da água, obstrução do fluxo da água para a geração de energia, impedimento à navegação, à pesca, aos esportes náuticos e pode auxiliar na proliferação de vetores de doenças, entre outros (Príncipe et al., 1997). Portanto, a vegetação aquática passa a ser considerada daninha em razão dos diversos problemas relacionados à utilização dos reservatórios, surgindo a partir desse momento a necessidade de aplicação de métodos de controle ou manejo.

Dentre as espécies que ocorrem com maior freqüência nos levantamentos realizados nos reservatórios das usinas hidrelétricas das regiões Sul, Sudeste e Nordeste do país, destacam-se em importância duas espécies imersas pertencentes à família Hydrocharitaceae: Egeria densa e Egeria najas. Contudo, nos últimos levantamentos florísticos realizados nos reservatórios das usinas hidrelétricas do Estado de São Paulo - Barra Bonita, Bariri, Ibitinga, Promissão, Nova Avanhandava, Três Irmãos, Jupiá, Ilha Solteira, Porto Primavera, Paraibuna e Jaguari - a espécie imersa Ceratophyllum demersum, pertencente à família Ceratophyllaceae, vem se destacando entre as 39 espécies de plantas daninhas aquáticas identificadas (Tanaka et al., 2002a; Bini \& Thomaz, 2005; Carvalho et al., 2005; Oliveira et al., 2005; Thomaz et al., 2006).

Essas espécies são originárias da América do Sul e multiplicam-se, principalmente, por fragmentação do caule, proporcionando sérios problemas em reservatórios de hidrelétricas e em lagos ou represas de pequeno porte, em decorrência da alta capacidade de reprodução e produção de biomassa (Bowmer et al., 1995; Kissmann \& Groth, 1997; Marcondes et al., 2003).

As espécies imersas E. densa e C. demersum também são encontradas em outros países e causam sérios problemas ao uso múltiplo da água (Bowmer et al., 1979; Madsen, 1998; Roberts et al., 1999).

Das alternativas de manejo de plantas daninhas aquáticas, destaca-se o uso de herbicidas; entretanto, no Brasil não existem opções de controle químico para uso em ambiente aquático; apenas o herbicida diquat está em fase de registro, diferentemente dos Estados Unidos, que possuem seis herbicidas registrados $(2,4-\mathrm{D}$, diquat, cobre, endothall, fluridone e glyphosate), utilizados no controle de plantas aquáticas (Haller, 1998).

O diquat é um herbicida de contato, nãoseletivo, inibidor do fotossistema I e pertencente ao grupo químico dos bipiridílios; demonstra elevado potencial para uso em ambientes aquáticos no controle de plantas daninhas emersas e imersas, em razão da sua segurança sobre os organismos aquáticos, ser pouco atraído aos materiais lipídicos e possuir baixas taxas de bioconcentração (Lavorenti, 1996; Rodrigues \& Almeida, 2005).

Contudo, o uso do diquat no controle de plantas imersas pode ser influenciado pelo fluxo de água nos reservatórios, pela degradação luminosa e pela adsorção com a matéria orgânica e partículas de argilas (Hofstra et al., 2001; Parsons et al., 2001; Velini et al., 2006).

Dessa maneira, o diquat torna-se mais eficiente quando utilizado em ambientes lênticos, por possibilitar a adequada absorção do herbicida pela planta (Bowmer et al., 1995; Velini et al., 2006). Em ambientes onde ocorre intenso fluxo de água, o controle das plantas imersas pode ser ineficiente, pelo fato de o tempo de permanência do herbicida em contato com a planta ser insuficiente para que haja absorção.

Em razão, em razão das poucas informações na literatura referentes ao período mínimo de exposição das plantas imersas de maior ocorrência nos reservatórios hidrelétricos da regiões Sul e Sudeste do Brasil ao herbicida diquat, para que ocorra controle satisfatório, 
torna-se fundamental a realização de estudos de controle químico que possam auxiliar nas tomadas de decisão de manejo dessas espécies.

O objetivo deste trabalho foi avaliar distintos períodos de exposição a diferentes concentrações do herbicida diquat no controle de E. densa, E. najase C. demersum.

\section{MATERIAL E MÉTODOS}

O experimento foi instalado e conduzido no Núcleo de Pesquisas Avançadas em Matologia (NUPAM), pertencente ao Departamento da Produção Vegetal da UNESP/campus de Botucatu-SP. As espécies avaliadas foram E. densa, E. najas e C. demersum. Foram testados seis períodos de exposição das plantas (30, 60, 120, 240, 480 e 960 minutos) a cinco concentrações do herbicida diquat $(0,075 ; 0,15$; 0,$3 ; 0,6$; e 1,2 ppm - produto comercial Reward $\left.240 \mathrm{~g} \mathrm{~L}^{-1}\right)$.

As espécies foram avaliadas individualmente, utilizando o delineamento experimental inteiramente casualizado, com quatro repetições, em esquema fatorial 6 × 5, além de uma testemunha sem a aplicação do diquat.

As plantas daninhas imersas foram seccionadas a $12 \mathrm{~cm}$ a partir do ápice, para obtenção das plantas, sendo coletadas no rio Tietê, em sua seção pertencente ao reservatório de Jupiá. Na instalação dos três experimentos utilizaram-se cinco soluções do herbicida com as concentrações testadas em vasos plásticos de $5 \mathrm{~L}$, nos quais as plantas foram inseridas e removidas após cada período de exposição determinado. Para evitar os efeitos da fotodegradação do herbicida e também para que as concentrações fossem mantidas, durante as 16 horas de exposição das plantas ao diquat foram realizadas quatro trocas de solução, em intervalos de três horas.

Após cada período de exposição, foram retiradas quatro plantas de cada solução e lavadas seqüencialmente em cinco vasos de $2 \mathrm{~L}$ contendo água destilada, cerca de seis vezes por vaso, sendo trocada a água destilada a cada tratamento, bem como a cada período de exposição. Em seguida, as plantas foram acondicionadas em tubos de ensaio de $250 \mathrm{ml}$ contendo solução de Hoagland $5 \%$, seguindo a metodologia utilizada por Tanaka et al. (2002b). Durante a avaliação do experimento, os tubos de ensaio permaneceram em casa de vegetação à temperatura de $26^{\circ} \mathrm{C}$.

As avaliações de controle das plantas daninhas imersas foram visuais, através de uma escala percentual de notas, em que 0 (zero) corresponde a nenhuma injúria demonstrada pela planta e 100 (cem) à morte das plantas, segundo a Sociedade Brasileira da Ciência das Plantas Daninhas - SBCPD (1995). As avaliações de controle foram realizadas aos $3,7,14$ e 21 dias após aplicação (DAA) do herbicida para E. densa, aos 2, 3 e 7 DAA para E. najas e aos 3, 7 e 14 DAA para $C$. demersum. Os parâmetros utilizados no estabelecimento das notas foram: inibição do crescimento, quantidade e uniformidade das injúrias e capacidade de rebrota das plantas. No final do experimento foi determinada a massa seca da planta inteira, para avaliar a porcentagem de redução da massa seca das plantas.

Os resultados foram submetidos à análise de variância pelo teste " $F$ " e submetidos à análise de regressão $(p>0,05)$. Os dados de porcentagem de redução da massa seca de plantas foram transformados em arco seno " $\mathrm{x} / 100$.

\section{RESULTADOS E DISCUSSÃO}

Na Figura 1 são apresentados os resultados de porcentagem de controle de plantas de E. densa em função do período de exposição a diferentes concentrações de diquat, aos 3, 7, 14 e 21 dias após a aplicação (DAA).

Observou-se aos 3 DAA aumento no controle da espécie com o incremento da concentração do diquat e com o período de exposição da planta ao herbicida, porém não ocorreu controle satisfatório sendo abaixo de $40 \%$. A partir dos 7 DAA, no periodo de exposição de 30 minutos ocorreu controle acima de $60 \%$ para as concentrações de 0,$15 ; 0,3 ; 0,6$; e 1,2 ppm; houve controle superior a $80 \%$ quando as plantas foram expostas ao diquat na concentração de $0,6 \mathrm{ppm}$ por um período de 960 minutos (16 horas).

Os resultados demonstraram, aos 14 DAA, controle satisfatório das plantas de E. densa (superior a 90\%) quando se utilizou a concentração de 0,075 ppm e o período de exposição 

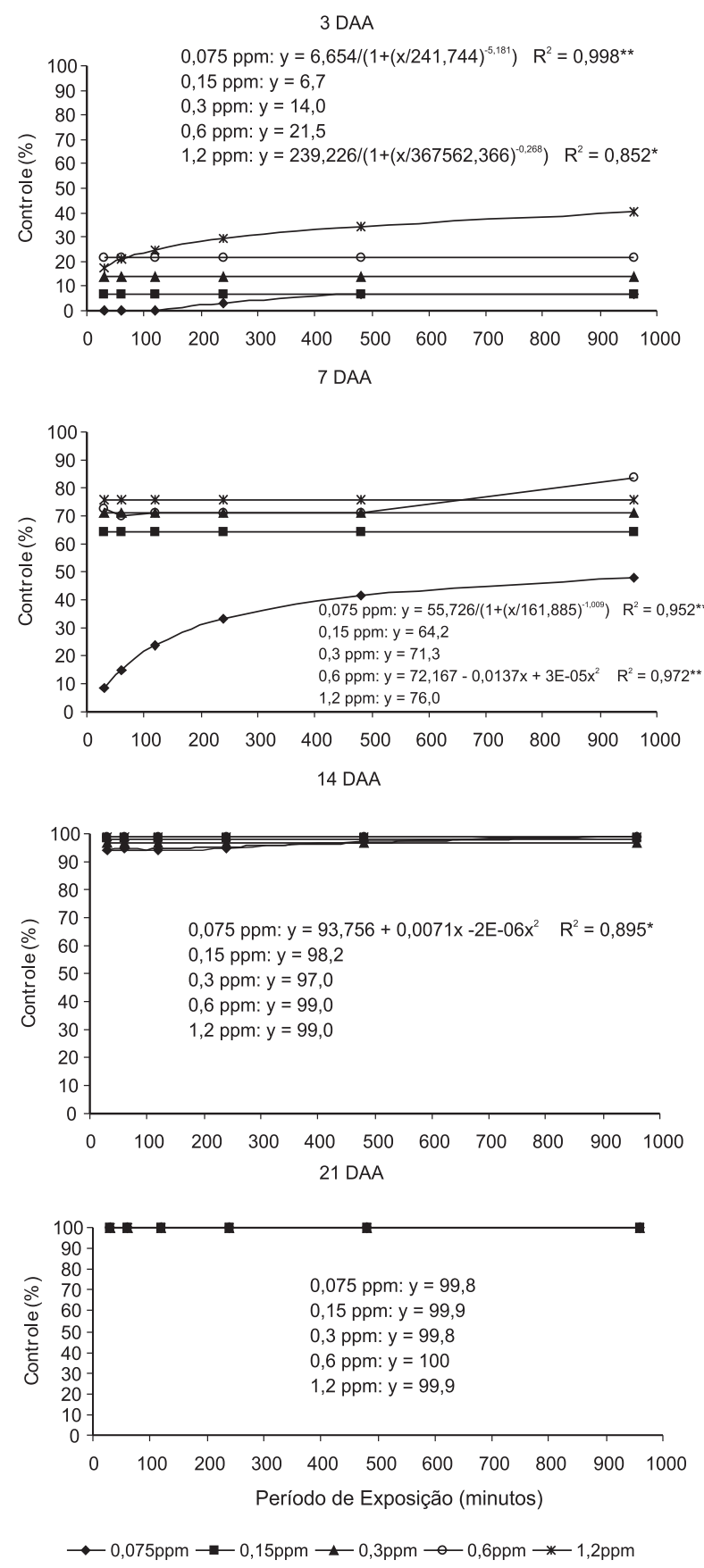

Figura 1 - Controle das plantas de E. densa em função do período de exposição a diferentes concentrações de diquat, aos 3, 7, 14 e 21 dias após a aplicação (DAA). Botucatu/ SP, 2006

da espécie ao diquat de 30 minutos. Contudo, com o aumento da concentração do herbicida, ocorreu também aumento da eficiência do controle, com médias de 99\% para as concentrações de 0,6 e 1,2 ppm no mesmo período de exposição. Da mesma forma, pode-se verificar que, aos $21 \mathrm{DAA}$, todas as concentrações de diquat foram eficientes no controle de $E$. densa, apresentando médias acima de $99,8 \%$ para o período de exposição da espécie ao diquat de 30 minutos.

O aparecimento do sintoma do diquat é rápido na presença de luz, na qual ocorre, no cloroplasto, a redução do íon bipiridílio a radical bipiridílio, liberando no processo água oxigenada (superóxidos); dessa forma, promove-se a oxidação de lipídeos, que têm como principal conseqüência a ruptura de membranas, levando à necrose de tecidos (Dodge, 1991; Hess, 1993; Nelson \& Getsinger, 2000; Rodrigues \& Almeida, 2005).

Na Tabela 1 está apresentado o resumo da análise estatística dos parâmetros de massa seca e da porcentagem de redução da massa seca de E. densa.

Tabela 1 - Resumo da análise estatística dos parâmetros de massa seca e da porcentagem de redução da massa seca de E. densa. Botucatu-SP, 2006

\begin{tabular}{|l|c|c|}
\hline \multicolumn{1}{|c|}{$\begin{array}{c}\text { Fonte de } \\
\text { variação }\end{array}$} & $\begin{array}{c}\text { Massa seca } \\
\left(\mathrm{g} \mathrm{planta}^{-1}\right)\end{array}$ & $\begin{array}{c}\text { Redução de } \\
\text { massa seca }(\%)\end{array}$ \\
\hline $\mathrm{F}_{\text {período }}(\mathrm{P})$ & $26,453^{* *}$ & $1,510^{\mathrm{ns}}$ \\
\hline $\mathrm{F}_{\text {concentração }}(\mathrm{C})$ & $40,777^{* *}$ & $11,255^{* *}$ \\
\hline $\mathrm{F}_{(\mathrm{Px})}$ & $1,386^{\mathrm{ns}}$ & $0,906^{\mathrm{ns}}$ \\
\hline $\mathrm{CV}(\%)$ & 37,45 & 15,07 \\
\hline
\end{tabular}

Pode-se verificar que não houve interação significativa entre o período de exposição e as concentrações do diquat. Contudo, houve redução da massa seca das plantas em todos os períodos de exposição com o aumento das concentrações de diquat avaliadas (Figuras 2 e 3 ).

Os dados ajustaram-se à equação de regressão somente para a porcentagem de redução da massa seca de plantas de E. densa em função das diferentes concentrações de diquat, aos 21 DAA (Figura 4).

No entanto, verificou-se tendência de ocorrer maiores reduções na massa seca das plantas à medida que se aumentaram-se as concentrações do herbicida diquat. Assim, as menores concentrações $(0,075$ e $0,15 \mathrm{ppm})$ de diquat proporcionaram reduções na massa 


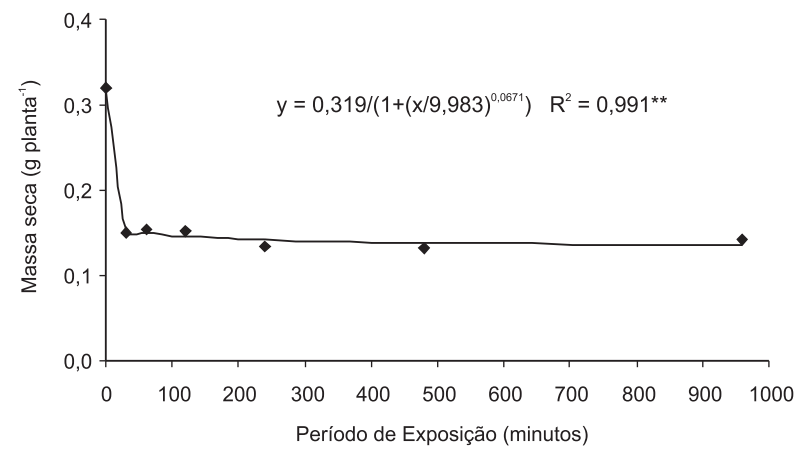

Figura 2 - Massa seca das plantas de E. densa, em função do período de exposição a diferentes concentrações de diquat, aos 21 dias após a aplicação. Botucatu-SP, 2006.

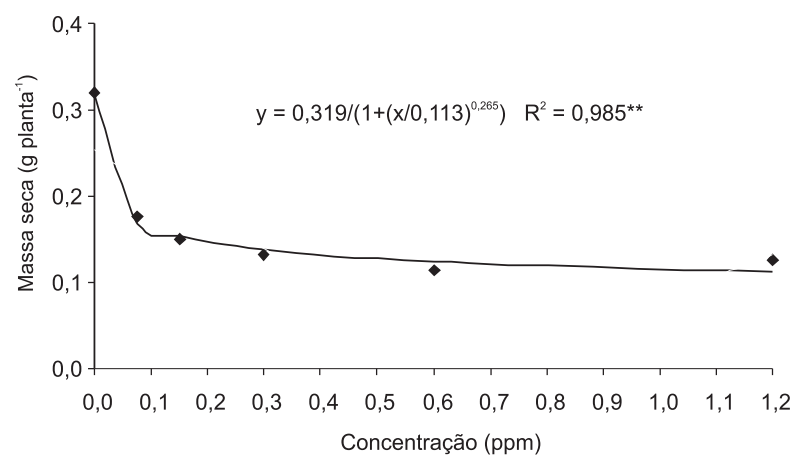

Figura 3 - Massa seca das plantas de E. densa, em função das diferentes concentrações de diquat, aos 21 dias após a aplicação. Botucatu-SP, 2006

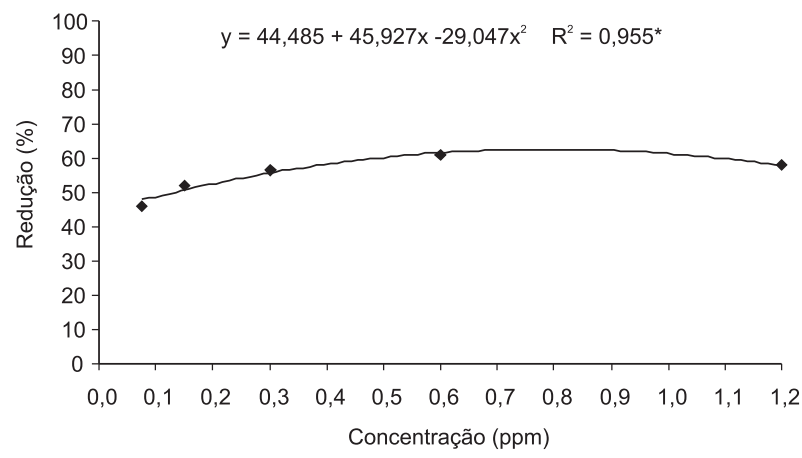

Figura 4 - Porcentagem de redução da massa seca de plantas de $E$. densa, em função das diferentes concentrações de diquat, aos 21 dias após a aplicação. Botucatu-SP, 2006.

seca das plantas em cerca de 46,3 e 52,3\%, respectivamente. Para as concentrações de 0,6 e 1,2 ppm de diquat houve reduções na massa seca na ordem de 60,8 e $57,9 \%$, respectivamente. Esses resultados demonstraram que com as menores concentrações do herbicida diquat $(0,075$ e $0,15 \mathrm{ppm})$ ocorre controle satisfatório da espécie $E$. densa a partir dos 14 DAA, sem o surgimento de rebrotas das plantas; aos $21 \mathrm{DAA}$, o controle pode atingir até $100 \%$ de eficiência (Figura 1).

Na Figura 5 são apresentados os resultados de porcentagem de controle de plantas de E. najas em função do período de exposição a diferentes concentrações de diquat, aos 2,3 e 7 DAA.

Verificou-se já aos 2 DAA tendência de aumento do controle da espécie à medida que ocorre o aumento da concentração, bem como quando houve o aumento do período de
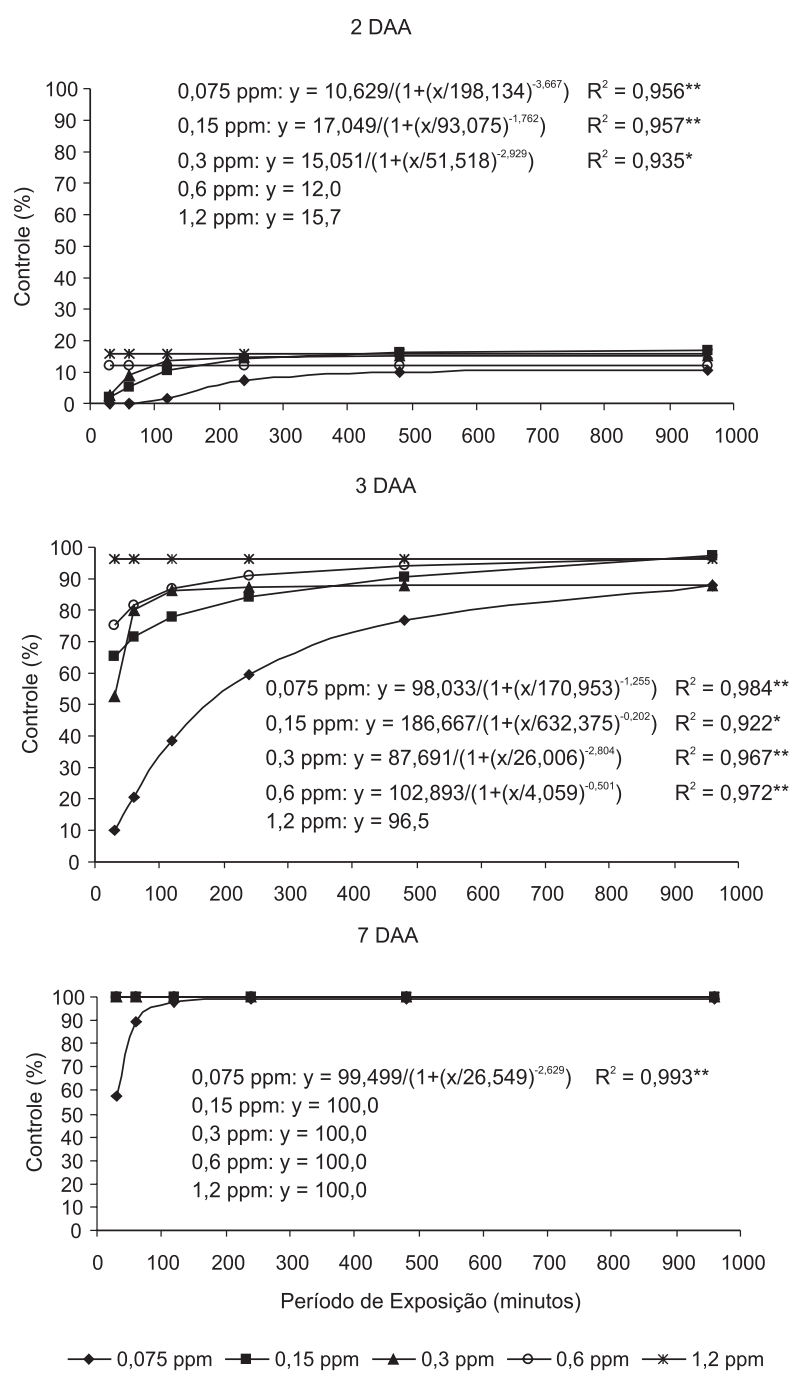

Figura 5 - Controle das plantas de E. najas, em função do período de exposição a diferentes concentrações de diquat, nos períodos de 2, 3 e 7 dias após a aplicação (DAA). Botucatu-SP, 2006.

Planta Daninha, Viçosa-MG, v. 26, n. 4, p. 865-874, 2008 
exposição da planta ao diquat; entretanto, o controle foi abaixo de $20 \%$. A partir dos 3 DAA, o período de exposição de 30 minutos proporcionou controle considerado satisfatório apenas para a concentração de $1,2 \mathrm{ppm}$, sendo superior a $95 \%$. As concentrações de 0,3 e 0,6 ppm apresentaram controle em torno de $80 \%$ a partir do período de exposição de 60 minutos aos 3 DAA; apenas a menor concentração de diquat $(0,075 \mathrm{ppm})$ não apresentou controle acima de $90 \%$ quando as plantas foram expostas por 960 minutos.

Já aos 7 DAA houve controle considerado excelente das plantas de $E$. najas, com eficiência de $100 \%$, a partir da concentração de $0,15 \mathrm{ppm}$ de diquat e do período de exposição de 30 minutos. Entretanto, apenas os dados da menor concentração de diquat $(0,075 \mathrm{ppm})$ ajustaram-se à equação de regressão. Ocorreu controle considerado satisfatório das plantas de E. najas, com média de $90 \%$, a partir do período de exposição da espécie ao diquat de 60 minutos. Dessa maneira, pode-se verificar que, aos 7 DAA, todas as concentrações de diquat foram eficientes no controle de E. najas, com médias acima de $95,0 \%$ a partir do período de exposição da espécie ao diquat de 120 minutos.

Na Tabela 2 está apresentado o resumo da análise estatística dos parâmetros de massa seca e da porcentagem de redução da massa seca de E. najas.

Tabela 2 - Resumo da análise estatística dos parâmetros de massa seca e da porcentagem de redução da massa seca de E. najas. Botucatu-SP, 2006

\begin{tabular}{|l|c|c|}
\hline $\begin{array}{c}\text { Fonte de } \\
\text { variação }\end{array}$ & $\begin{array}{c}\text { Massa seca } \\
\left(\mathrm{g} \mathrm{planta}^{-1}\right)\end{array}$ & $\begin{array}{c}\text { Redução de } \\
\text { massa seca }(\%)\end{array}$ \\
\hline $\mathrm{F}_{\text {período }}(\mathrm{P})$ & $6,505^{* *}$ & $0,992^{\mathrm{ns}}$ \\
\hline $\mathrm{F}_{\text {concentração }}(\mathrm{C})$ & $11,138^{* *}$ & $4,755^{* *}$ \\
\hline $\mathrm{F}_{(\mathrm{Px})}$ & $0,683^{\mathrm{ns}}$ & $0,670^{\mathrm{ns}}$ \\
\hline $\mathrm{CV}(\%)$ & 40,41 & 40,52 \\
\hline
\end{tabular}

Não houve interação significativa entre o período de exposição e as concentrações do diquat. A massa seca das plantas de E. najas foi reduzida em todos os períodos de exposição, bem como com o aumento das concentrações de diquat avaliadas (Figuras 6 e 7). Contudo, houve ajuste à equação de regressão apenas

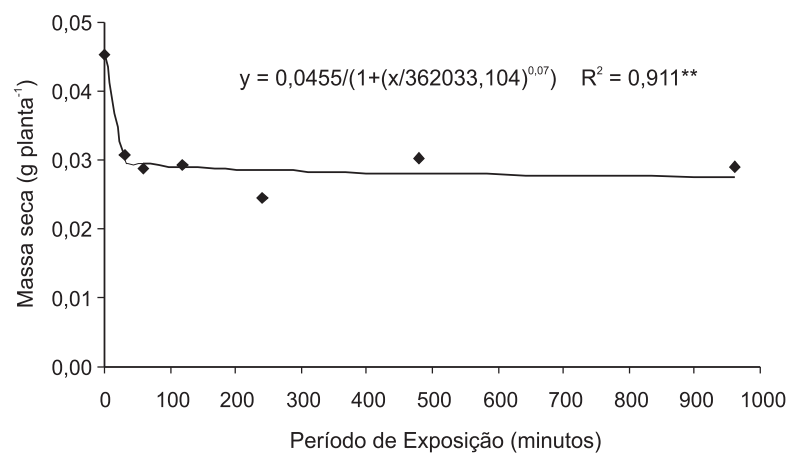

Figura 6 - Massa seca das plantas de E. najas, em função do período de exposição a diferentes concentrações de diquat, aos 7 dias após a aplicação. Botucatu-SP, 2006

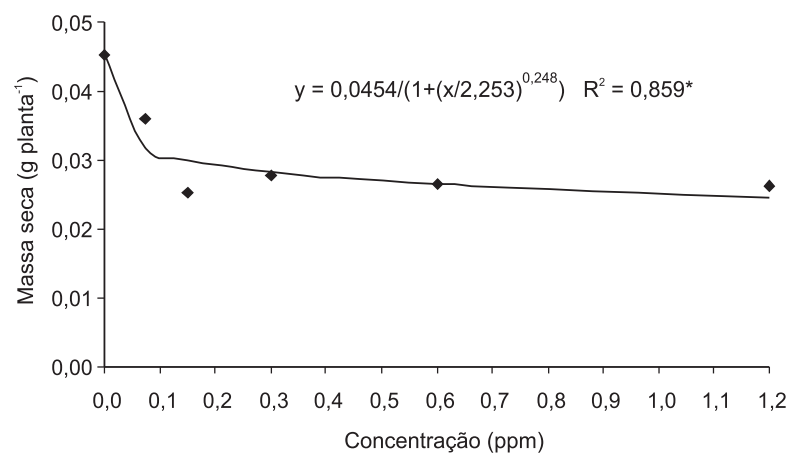

Figura 7 - Massa seca das plantas de E. najas, em função das diferentes concentrações de diquat, aos 7 dias após a aplicação. Botucatu-SP, 2006

para os dados de porcentagem de redução da massa seca de plantas de $E$. najas em função das diferentes concentrações de diquat, aos 7 DAA (Figura 8).

Assim como observado para E. densa, verificou-se tendência de haver maior redução na massa seca das plantas de E. najas à medida que se aumentaram as concentrações do herbicida diquat. Dessa forma, as concentrações de diquat proporcionaram reduções na massa seca das plantas de $24,3 \%$ para a menor concentração, e as demais concentrações de diquat promoveram redução média na massa seca na ordem de $48,6 \%$.

Esses resultados demonstraram que apenas 30 minutos de exposição à concentração de 1,2 ppm do herbicida diquat foi suficiente para que ocorresse controle satisfatório da espécie E. najas a partir dos 3 DAA. Entretanto, a concentração de $0,075 \mathrm{ppm}$ apresentou 


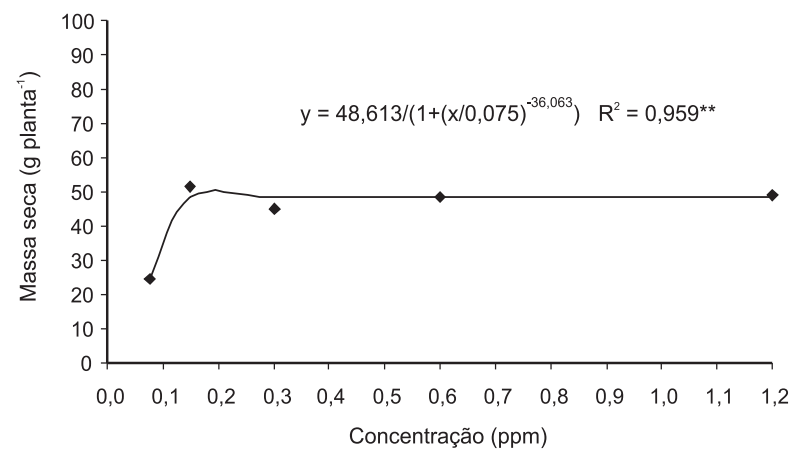

Figura 8 - Porcentagem de redução da massa seca de plantas de E. najas, em função das diferentes concentrações de diquat, aos 7 dias após a aplicação. Botucatu-SP, 2006.

rebrota em algumas plantas no período de exposição de 30 minutos aos 7 DAA; o controle pode atingir até $100 \%$ de eficiência a partir da concentração de $0,15 \mathrm{ppm}$, considerando o mesmo período de exposição (Figura 5).

Na Figura 9 são apresentados os resultados de porcentagem de controle de plantas de C. demersum em função do período de exposição a diferentes concentrações de diquat, aos 3,7 e 14 DAA. Houve tendência de se aumentar o controle à medida que ocorreu aumento da concentração, assim como quando houve aumento do periodo de exposição da planta ao diquat, observado para as duas espécies de egéria. O mesmo também foi verificado para C. demersum, a partir dos 3 DAA, que apresentou controle acima de $70 \%$ para as concentrações superiores a 0,15 ppm de diquat. Contudo, apenas os dados das concentrações de 0,6 e $1,2 \mathrm{ppm}$ ajustaram-se às equações de regressão.

Aos 7 DAA, não houve ajuste às equações de regressão para os dados obtidos de controle, porém houve controle considerado excelente (99\%) para as concentrações de 0,15; 0,3; 0,6; e $1,2 \mathrm{ppm}$ e controle superior a $90 \%$ quando as plantas foram expostas à concentração de 0,075 ppm de diquat.

Da mesma forma, aos 14 DAA não houve ajuste às equações de regressão para os dados obtidos de controle; as concentrações de 0,15; 0,$3 ; 0,6$; e 1,2 ppm de diquat foram eficientes no controle de $C$. demersum, com eficiência de $100 \%$, enquanto a concentração de 0,075 ppm mostrou eficiência de 99,2\%.
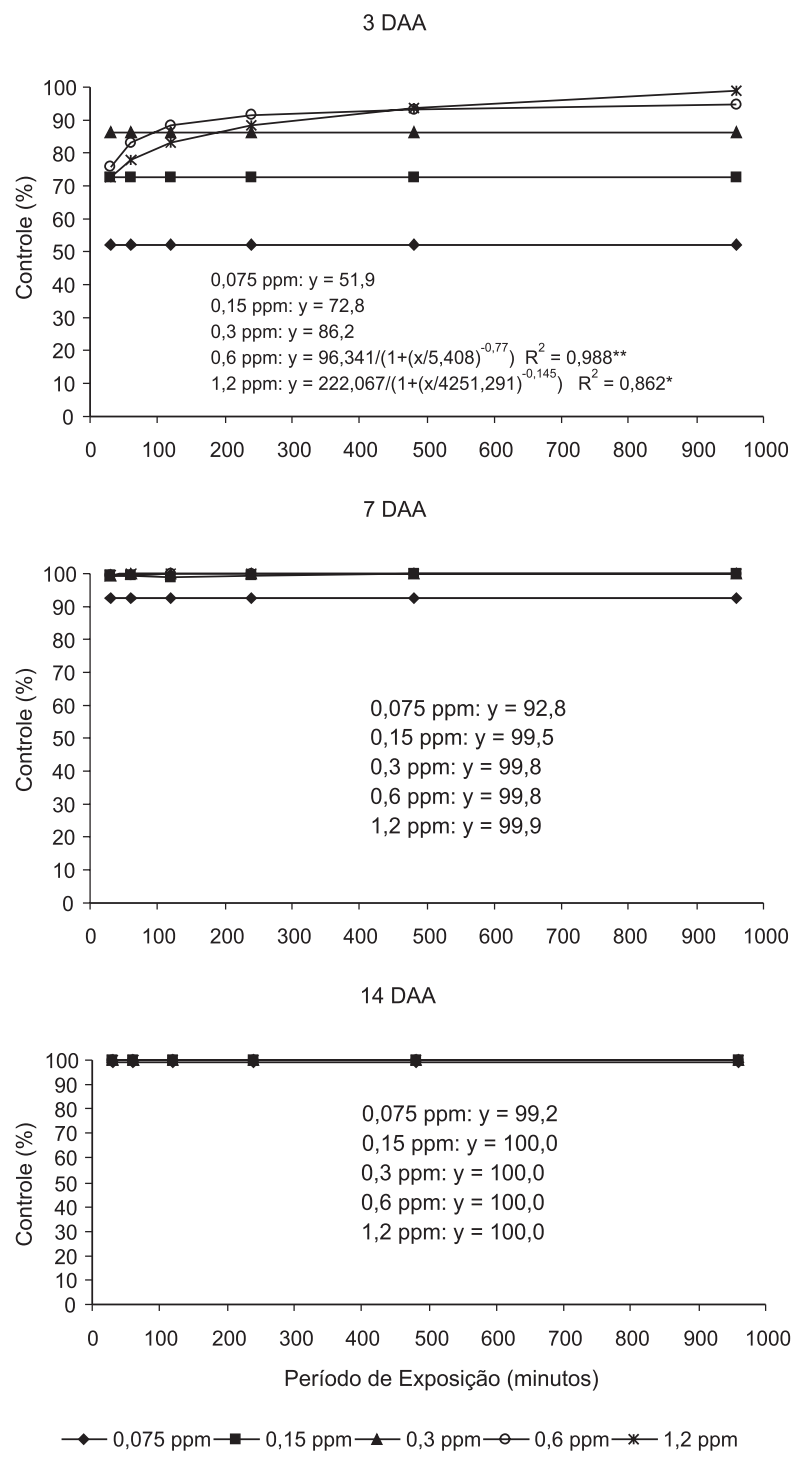

Figura 9 - Controle das plantas de C. demersum, em função do período de exposição a diferentes concentrações de diquat, aos 3, 7 e 14 dias após a aplicação (DAA). BotucatuSP, 2006

É apresentado na Tabela 3 o resumo da análise estatística dos parâmetros de massa seca e da porcentagem de redução da massa seca de $C$. demersum. Houve interação significativa entre o período de exposição e as concentrações do diquat.

Ocorreu redução da massa seca das plantas de C. demersum em todos os períodos de exposição e em todas as concentrações de diquat avaliadas (Figuras 10 e 11). Entretanto, apenas os períodos de exposição de 120, 240 e 480 minutos ajustaram-se às equações de 
Tabela 3 - Resumo da análise estatística dos parâmetros de massa seca e da porcentagem de redução da massa seca de C. demersum. Botucatu-SP, 2006

\begin{tabular}{|l|c|c|}
\hline $\begin{array}{c}\text { Fonte de } \\
\text { variação }\end{array}$ & $\begin{array}{c}\text { Massa seca } \\
\left(\mathrm{g} \text { planta }^{-1}\right)\end{array}$ & $\begin{array}{c}\text { Redução de } \\
\text { massa seca }(\%)\end{array}$ \\
\hline $\mathrm{F}_{\text {período }}(\mathrm{P})$ & $37,646^{* *}$ & $8,529^{\mathrm{ns}}$ \\
\hline $\mathrm{F}_{\text {concentração }}(\mathrm{C})$ & $50,675^{* *}$ & $6,453^{* *}$ \\
\hline $\mathrm{F}_{(\mathrm{Px})}$ & $2,421^{\mathrm{ns}}$ & $1,461^{\mathrm{ns}}$ \\
\hline $\mathrm{CV}(\%)$ & 29,89 & 18,08 \\
\hline
\end{tabular}

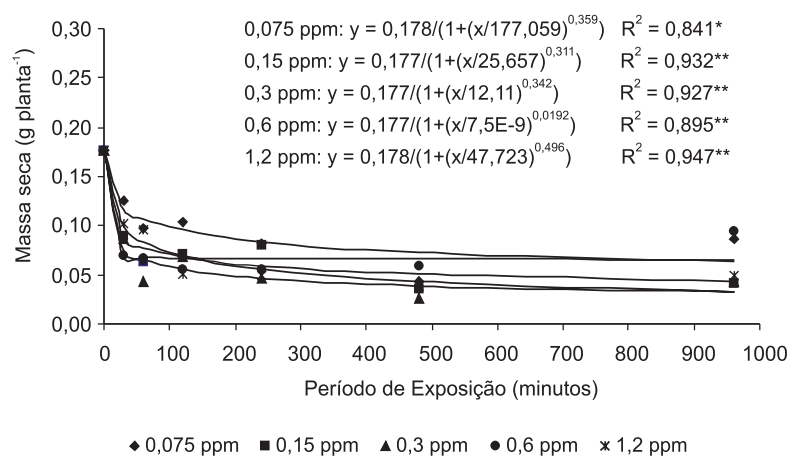

Figura 10 - Massa seca das plantas de C. demersum, em função do período de exposição a diferentes concentrações de diquat, aos 14 dias após a aplicação. Botucatu-SP, 2006.

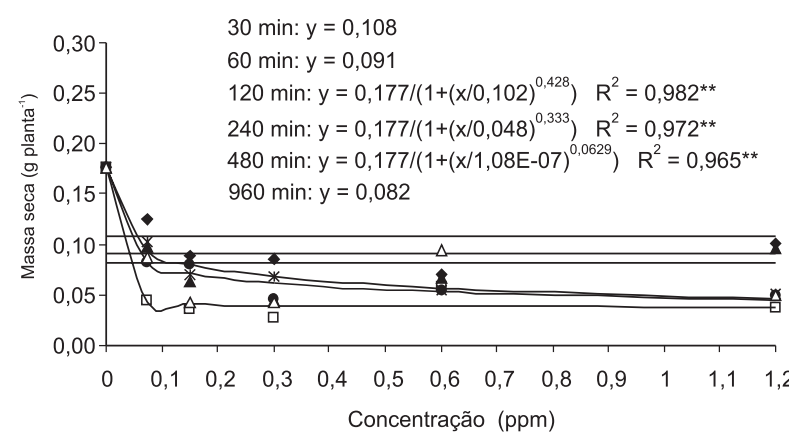

- $30 \min \Delta 60 \min * 120 \min \bullet 240 \min \square 480 \min \Delta 960 \min$

Figura 11 - Massa seca das plantas de C. demersum, em função das diferentes concentrações de diquat, aos 14 dias após a aplicação. Botucatu-SP, 2006.

regressão em função das diferentes concentrações de diquat, aos 14 DAA (Figura 11).

Para os dados de porcentagem de redução da massa seca de plantas, houve ajuste apenas para os períodos de exposição ao diquat, aos 14 DAA (Figura 12).

Da mesma forma que foi observada para as espécies de egéria, verificou-se tendência

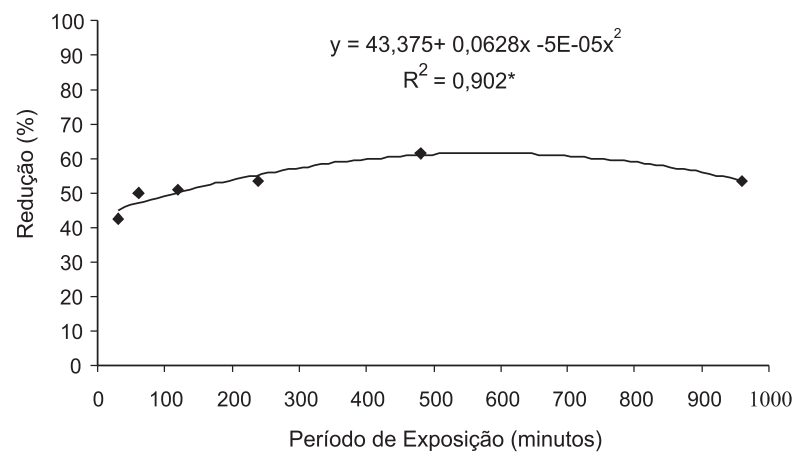

Figura 12 - Porcentagem de redução da massa seca de plantas de $C$. demersum, em função do período de exposição a diferentes concentrações de diquat, aos 14 dias após a aplicação. Botucatu-SP, 2006

de ocorrer maiores reduções na massa seca das plantas com o aumento nas concentrações e o período de exposição da espécie ao herbicida diquat. Pode-se verificar na Figura 13 que as concentrações de diquat proporcionaram reduções na massa seca das plantas de $52,1 \%$.

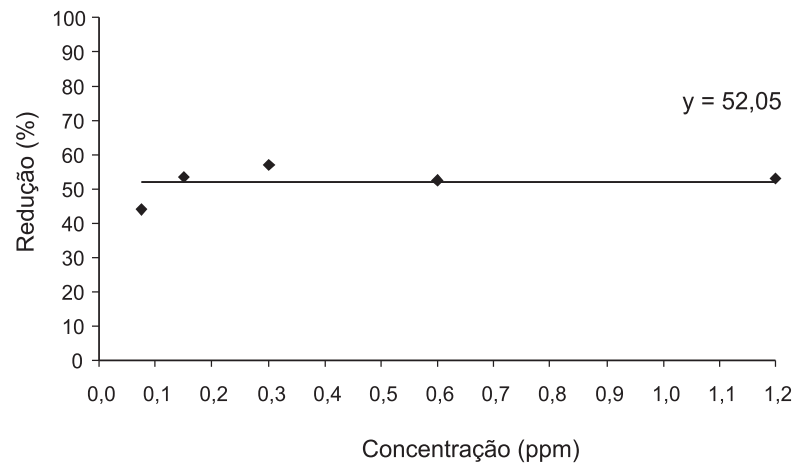

Figura 13 - Porcentagem de redução da massa seca de plantas de $C$. demersum, em função das diferentes concentrações de diquat, aos 14 dias após a aplicação. Botucatu-SP, 2006

Esses resultados demonstraram que apenas 30 minutos de exposição à concentração de 0,075 ppm do herbicida diquat foi suficiente para proporcionar controle considerado satisfatório de C. demersum a partir dos 7 DAA; o controle pode atingir até $100 \%$ de eficiência quando se utilizam concentrações superiores a 0,3 ppm para o mesmo período de exposição. Todavia, a concentração de 0,075 ppm apresentou rebrota em algumas plantas nos periodos de exposição de 30 e 60 minutos aos 14 DAA (Figura 9). 
Diversos trabalhos evidenciaram dificuldades no controle químico das plantas daninhas aquáticas imersas E. densa, E. najas e C. demersum, em decorrência de fatores referentes a degradação ou inativação da molécula do herbicida, o que pode proporcionar a rebrota das plantas após alguns dias da aplicação do diquat e a necessidade de reaplicações (Hofstra et al., 2001; Poovey \& Getsinger, 2002; Martins et al., 2005).

De acordo com Martins et al. (2005), concentrações de diquat inferiores a $0,25 \mathrm{ppm}$ foram ineficientes no controle de $E$. densa e E. najas após 45 dias de exposição das plantas ao herbicida em condições de caixas-d'água, discordando dos resultados obtidos no presente trabalho, em razão de as condições deste experimento serem mais favoráveis nas determinações das variáveis estudadas. Da mesma forma, Tanaka et al. (2002b) relatam que a utilização do diquat no controle de E. densa e E. najas, em concentrações acima de 0,1 ppm, é inviabilizada em manejos fundamentados em uma única aplicação, considerando a aplicação do herbicida em ambiente natural de ocorrência das espécies.

Velini et al. (2006), avaliando o controle de espécie $E$. najas em uma lagoa, verificaram que a concentração de 1,04 ppm de diquat promoveu controle total da espécie aos 7 DAA e, após oito meses da aplicação, não foi observada a recolonização da lagoa pela espécie. Hofstra et al. (2001) afirmam que as plantas de $C$. demersum apresentaram controle de $100 \%$ quando expostas por um período de oito dias ao diquat, em condições de tanques sem a presença de partículas de sedimentos em suspensão na água. Segundo Poovey \& Getsinger (2002), doses de 1 a 2 ppm de diquat promoveram controle satisfatório de plantas de E. densa em aplicações em tanques com turbidez inferior a 15 UNT (Unidade Nefelométrica de Turbidez); entretanto, os autores ressaltam que turbidez elevada ( $>25$ UNT) da água pode reduzir significativamente a eficácia do herbicida diquat.

Entretanto, com base nos resultados obtidos no presente trabalho, pode-se concluir que apenas 30 minutos de exposição das espécies imersas $E$. densa e $C$. demersum à concentração de $0,075 \mathrm{ppm}$ foi suficiente para proporcionar controle excelente aos 21 e 14 DAA, respectivamente; para controle de $E$. najas aos 7 DAA houve necessidade de um período maior que 120 minutos de exposição, considerando a mesma concentração do herbicida. Esses resultados corroboram os obtidos por Velini et al. (2006), que ressaltam o grande potencial de uso do diquat no controle de plantas daninhas aquáticas imersas em locais que apresentam rápida renovação de água.

Apesar do grande potencial hídrico que o Brasil apresenta e dos prejuízos que essas espécies causam ao uso múltiplo da água, existem poucos estudos realizados no País acerca do assunto. Portanto, há necessidade de intensificar os estudos sobre a biologia e ecologia dessas espécies, assim como aumentar as opções de moléculas de herbicidas para uso em ambientes aquáticos, para melhorar a eficiência e minimizar os efeitos sobre os outros organismos aquáticos, além de determinar o impacto da decomposição do material vegetal no corpo hídrico após ter sido submetido ao controle químico.

\section{LITERATURA CITADA}

BINI, L. M.; THOMAZ, S. M. Prediction of Egeria najas and Egeria densa occurrence in a large subtropical reservoir (Itaipu Reservoir, Brazil-Paraguay). Aquatic Bot., v. 83, p. $227-238,2005$.

BOWMER, K. et al. Identification, biology and management of Elodea canadensis, Hidrocharitaceae. J. Aquatic Plant Manag., v. 3, n. 1, p. 13-19, 1995.

BOWMER, K. et al. Management of elodea in australian irrigation systems. J. Aquatic Plant Manag., v. 17, n. 1, p. 4-12, 1979.

CARVALHO, F. T. et al. Influência da turbidez da água do Rio Tietê na ocorrência de plantas aquáticas. Planta Daninha, v. 23. n. 2, p. 359-362, 2005.

DODGE, A. D. Photosyntehesis. In: KIRKWOOD, R. C. Target sites for herbicide action. Glasgow: University of Stranthclyde, 1991. p. 1-56.

HALLER, W. T. Options for mechanical and chemical aquatic weed control. In: CONGRESSO BRASILEIRO DA CIÊNCIA DAS PLANTAS DANINHAS -WORKSHOP DE PLANTAS AQUÁTICAS, 21., 1998, Brasília. Resumos... Brasília: Sociedade Brasileira da Ciência das Plantas Daninhas 1998. p. 46-53.

Planta Daninha, Viçosa-MG, v. 26, n. 4, p. 865-874, 2008 
HESS, F. D. Herbicide effects on plant structure, physiology, and biochemistry. In: ALTMAN, J. Pesticide interactions in crop production beneficial and deleterious effects. London: CRC Press, 1993. 579 p.

HOFSTRA, D. E. et al. Evaluation of selected herbicides for the control of exotic submerged weeds in New Zealand: II. The effects of turbidity on diquat and endothall efficacy. J. Aquatic Plant Manag., v. 39, n. 1, p. 25-27, 2001.

KISSMANN, K. G.; GROTH, D. Plantas infestantes e nocivas. 2.ed. São Paulo: BASF, 1997. 825 p.

LAVORENTI, A. Comportamento dos herbicidas no meio ambiente. In: WORKSHOP SOBRE BIODEGRADAÇÃO, 1996, Campinas. Anais... Jaguariúna: Embrapa-CNPMA, 1996. p. 81-92.

MADSEN, J. D. Overview of the ecological assessment technology area. J. Aquatic Plant Manag., v. 36, p. 25-27, 1998.

MARCONDES, D. A. S. et al. Estudos para manejo integrado de plantas aquáticas no reservatório de Jupiá In: THOMAS, S. M.; BINI, L. M. (Eds.) Ecologia e manejo de macrófitas aquáticas. Maringá: EDUEM, 2003. p. 299317.

MARTINS, D. et al. Controle de Egeria densa e Egeria najas em caixa d'água utilizando o herbicida diquat. Planta Daninha, v. 23, n. 2, p. 381-385, 2005.

NELSON, L. S.; GETSINGER, K. D. Herbicide evaluation for control of wild taro. J. Aquatic Plant Manag., v. 38, n. 1, p. 70-72, 2000.

OLIVEIRA, N. M. B. et al. Capacidade de regeneração de Egeria densa nos reservatórios de Paulo Afonso, BA. Planta Daninha, v. 23, n. 2, p. 363-396, 2005.

PARSONS, J. K. et al. The use 2,4-D for selective control of an early infestation of eurasian watermilfoil in Loon lake, Washington. J. Aquatic Plant Manag., v. 39, n. 1, p. 117$125,2001$.
POOVEY, A. G.; GETSINGER, K. D. Impacts of inorganic turbidity on diquat efficacy against Egeria densa. J. Aquatic Plant Manag., v. 40, n. 1, p. 6-10, 2002.

PRÍNCIPE, C. R. et al. Impactos da afluência de elódeas na operação e manutenção da usina hidroelétrica Eng. Souza Dias (Jupiá)-CESP. In: CONGRESSO BRASILEIRO DA CIÊNCIA DAS PLANTAS DANINHAS - WORKSHOP DE PLANTAS AQUÁTICAS, 21.,1997, Caxambu-MG. Resumos... Caxambu: Sociedade Brasileira da Ciência das Plantas Daninhas, 1997. p. 5-8.

ROBERTS, D. E. et al. Invasion of Egeria into the Hawkesbury-Nepean River, Australia. J. Aquatic Plant Manag., v. 37, n. 1, p. 31-34, 1999.

RODRIGUES, B. N.; ALMEIDA, F. S. Guia de herbicidas. 5.ed. Londrina: 2005. 592 p.

SOCIEDADE BRASILEIRA DA CIÊNCIA DAS PLANTAS DANINHAS - SBCPD. Procedimentos para instalação, avaliação e análise de experimentos com herbicidas. Londrina: 1995. 42 p.

TANAKA, R. H. et al. Ocorrência de plantas aquáticas nos reservatórios da Companhia Energética de São Paulo. Planta Daninha, v. 20, p. 101-111, 2002a.

TANAKA, R. H. et al. Avaliação de herbicidas para o controle de Egeria em laboratório, caixa d'água e represa sem fluxo de água. Planta Daninha, v. 20, n. 1, p. 64-72, 2002b.

THOMAZ, S. M. et al. Effect of reservoir drawdown on biomass of three species of aquatic macrophytes in a large sub-tropical reservoir (Itaipu, Brazil). Hydrobiologia, v. 570, p. 53-59, 2006.

VELINI, E. D. et al. Avaliação da eficiência do diquat no controle de plantas aquáticas submersas. In: CONGRESSO BRASILEIRO DA CIÊNCIA DAS PLANTAS DANINHAS, 25., 2006, Brasília. Resumos... Brasília: Sociedade Brasileira da Ciência das Plantas Daninhas, 2006. CD-ROM 